\title{
Mechanisms of Cell Accumulation Induced by Mycobacterium bovis BCG
}

\section{Octávio Menezes-de-Lima-Júnior, Maria das Graças MO Henriques ${ }^{+}$}

\author{
Laboratório de Farmacologia Aplicada, Far-Manguinhos, Fiocruz, Rua Sizenando Nabuco 100, 21041250
} Rio de Janeiro, RJ, Brasil

\begin{abstract}
Mycobacteria, specially Mycobacterium tuberculosis are among the micro-organisms that are increasing dramatically the number of infections with death, all over the world. A great number of animal experimental models have been proposed to investigate the mechanisms involved in the host response against these intracellular parasites. Studies of airway infection in guinea-pigs and rabbits, as well as, in mice intravenously infected with BCG have made an important contribution to our understanding of the virulence, pathogenesis and the immunology of mycobacterial infections. Although, there are few models to study the mechanisms of the initial inflammatory process induced by the first contact with the Mycobacteria, and the relevance of the acute generation of inflammatory mediators, cytokines and leukocyte infiltration to the development of the mycobacterial infection. In this work we reviewed our results obtained with a model of $\mathrm{M}$. bovis $B C G$-induced pleurisy in mice, describing the mechanisms involved in the leukocyte influx induced by BCG at $24 \mathrm{hr}$. Different mechanisms appear to be related with the influx of neutrophils, eosinophils and mononuclear cells and distinct inflammatory mediators, cytokines and adhesion molecules are involved in the BCG-induced cell accumulation.
\end{abstract}

Keywords: animal models - Mycobacteria - Mycobacterium bovis BCG - inflammation - leukocyte accumulation - pleurisy

Over a century ago, Robert Koch identified Mycobacterium tuberculosis as the causative agent of tuberculosis in humans. He was the first to realise that the efficacy of his early therapies with soluble extracts of M. tuberculosis depended largely on the patient's immune-cell response.

Mycobacteria, specially $M$. tuberculosis are among the micro-organisms that are increasing dramatically the number of infections with death, all over the world (Chrétien 1995).

Mycobacteria are small, aerobic, gram-positive, acid-fast, nonmotile and nonspore-forming bacilli. They consist of a large group including pathogenic, non-pathogenic, and saprophytic species that commonly are of environmental origin (Hines II 1995). Characteristically, mycobacteria presents a complex cell wall associated to the membrane. The cell wall structure and composition (Fig. 1) is related to the ability of the intracellular parasitic species of mycobacteria to survive in the hostile environment of the phagossome of macrophages, as well as with the cytotoxic and immunological effects

\footnotetext{
This work was supported by grants from $\mathrm{CNPq}$ and CAPES (Brazil).

${ }^{+}$Corresponding author. Fax: $+55.21-270.3912$. E-mail: henrique@gene.dbbm.fiocruz.br

Received 3 September 1997

Accepted 30 September 1997
}

of these micro-organisms. (Fenton \& Vermeulen 1996).

Tuberculosis infection is caused by $M$. tuberculosis, M. bovis or M. africanum. Because of its close phylogenetic and pathogenic relationship, they were grouped as the $M$. tuberculosis complex (MTC) and are considered to be interchangeable as etiologic agents of human and animal tuberculosis (Griffin et al. 1995).

While tuberculosis represents nowadays the most threatening disease caused by intracellular bacteria, our understanding of the cellular and molecular interactions between mycobacteria and host cells is far from complete.

The initial events during a primary pulmonary infection with MTC are poorly understanding and there are few models to evaluate the sequence of events that follows the first contact of the host with the mycobacteria.

In this article, we review the current state of understanding of the early events that happen during the primary contact with mycobacteria.

\section{ANIMAL MODELS}

Studies with laboratory animals (guinea-pigs and rabbits) have significantly enhanced our understanding of the aetiology and pathogenesis of tuberculosis. Humans, cattle, deer, guinea-pigs and rabbits have similar pathology, but differ in their susceptibility to tuberculosis (Smith \& Wiegeshaus 


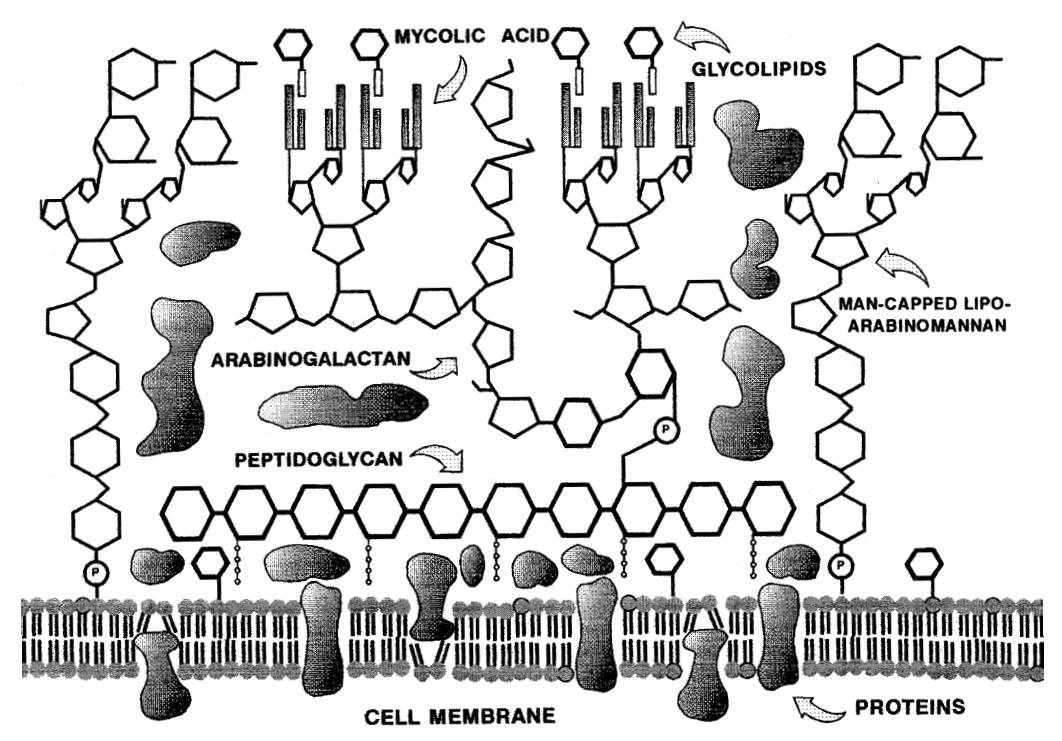

Fig. 1: the Mycobacterium tuberculosis cell wall. Adapted from the structure proposed by Fenton and Vermeulen ( 1996).

1989). Although studies in guinea-pig and rabbit have made an important contribution to our understanding of the virulence and pathogenesis of tuberculosis, they have limited use for the study of the protective immune response (Dannemberg 1991, Griffin et al. 1995).

Since 1970, mice have largely replaced guineapigs and rabbits as the animal model to study the immunology of mycobacterial infections. Most of the studies on the role of macrophages and monocytes and its interaction with $\mathrm{T}$ cells were done in mice intravenously infected with BCG (Kaufmann 1993).

\section{THE EARLY EVENTS}

The initial events during a primary pulmonary infection with MTC are poorly understood and there are few models to evaluate the sequence of events that follow the first contact of the host with the mycobacteria. We have recently described the experimental model of mouse pleurisy induced by M. bovis BCG. We used the pleural cavity of the mouse because is a straightforward and well-established model (Henriques et al. 1990, 1996, Bozza et al. 1994).

The injection of $M$. bovis BCG into mouse pleural cavity induces an intense biphasic inflammatory reaction that peaks at $24 \mathrm{hr}$ and 15 days. At 4 $\mathrm{hr}$ occurs an influx of neutrophils that is maximal at $24 \mathrm{hr}$. At this time it is also observed an intense influx of eosinophils and mononuclear cells. Another leukocyte influx is observed at 15 days composed by mononuclear cells and some neutrophils (Menezes-de-Lima-Junior et al. 1997).
Neutrophils are the predominant leukocytes to arrive at sites of acute inflammation, capable of defending the host against bacterial infections. Neutrophils accumulation is also intimately associated with oedema formation and the recruitment of other phagocytic leukocytes such as monocytes (Nourshargh 1993). The neutrophil influx induced by i.t. BCG is in accordance to the description of neutrophil migration to peritoneal cavity of rabbits inoculated with BCG (Appelberg 1992) and to rabbit pleural cavity after BCG instillation (Antony et al. 1985). Furthermore, neutrophils are described in pleural exudate of tuberculosis patients (Montgomery \& Lemon 1933).

Eosinophils are also capable of phagocyte and killing bacteria in vitro, and have a specialised role in the inflammatory process involved in protective responses against helmintic parasites (Nourshargh 1993). Furthermore has been recently reported that eosinophils accumulate in pleural cavity after injection of endotoxin (Bozza et al. 1993) suggesting an involvement of these cells in pulmonary inflammation induced by bacterial products. On the other hand, eosinophil accumulation induced by mycobacteria is poorly described. Although eosinophilia is observed sometimes in broncoalveolar lavage of tuberculosis patients (Vijayan et al. 1992, Nakamura et al. 1993), eosinophil accumulation induced by $M$. tuberculosis or M. bovis BCG in animal experimental models has not been described so far. However, Castro et al. (1991) have described that M. avium or $M$. smegmatis are able to induce eosinophil accumulation in mouse air pouch. 
We have analysed the inflammatory mediators and cytokine involved in eosinophil accumulation induced by BCG comparing with those involved in neutrophil accumulation (Fig. 3). Lipoxygenase products, PAF-acether and interleukin-5 seem to be involved in eosinophil accumulation (Menezesde Lima-Júnior et al. 1996, 1997).

PAF and LTB4 can activate both neutrophils and eosinophils and are able to induce in vivo eosinophil and neutrophil accumulation in different models (Wardlaw et al. 1986, Czarnetzki \& Csato 1989, Martins et al. 1989, Silva et al. 1991). The participation of lipid mediators (PAF and leukotrienes) and cytokines such as IL-8, TNF, IL1 and GM-CSF in neutrophil accumulation to inflammatory focus It is well known (Nourshargh 1993). However our results show that PAF and derivative products from cyclo and lipoxygenase are not involved in neutrophil influx at $24 \mathrm{hr}$ after BCG i.t.. It is noteworthy that neutrophil influx presented $4 \mathrm{hr}$ after BCG is inhibited by the PAF antagonist WEB 2170, suggesting a differential mechanism of neutrophil migration at 4 and $24 \mathrm{hr}$ after BCG-induced pleurisy (Menezes-de-LimaJúnior et al. 1997).

At $24 \mathrm{hr}$, only dexamethasone or L-NAME were able to inhibit the neutrophil accumulation as well as eosinophil influx (Menezes-de-Lima Júnior et al. 1997). The participation of NO in leukocyte chemotaxis in vitro has been investigated (Kaplan et al. 1989, Belenky et al. 1993) although a few in vivo studies have been performed with eosinophil (Teixeira et al. 1993, Ferreira et al. 1996). The sources of NO are probably the macrophages from the pleural cavity. It is known that mouse pleural macrophages can phagocyte $M$. bovis BCG in vitro (Zlotnik \& Crowde 1982). It was also described that peritoneal macrophages from M. bovis BCG-infected mice produces nitric oxide (Saito \& Nakano 1996). We have also demonstrated that pleural macrophages from mice injected i.t. with BCG, produces significant levels of NO in contrast to resident macrophages (Werneck-Barroso et al. 1996)

The treatment with a neutralising monoclonal antibody $(\mathrm{mAb})$ anti-TNF- $\alpha$ has indicated that this cytokine is involved in neutrophil but not eosinophil migration induced by BCG pleurisy (Menezesde-Lima-Júnior et al. 1997). A number of cytokines can regulate the accumulation and activation of neutrophils and eosinophils. TNF acts on endothelial cells to enhance their interaction with neutrophils and eosinophils. The dose-response relationship and kinetics of TNF-stimulated endothelial cell adhesiveness for neutrophils is similar to that for eosinophils (Nourshargh 1993). However, in our results with BCG induced-pleurisy, TNF- $\alpha$ seems to have a more important effect on neutrophil migration (Menezes-de-Lima-Junior et al. 1997). It was recently demonstrated that TNF- $\alpha$ produced by macrophages in response to PPD (the soluble antigen released from $M$. tuberculosis) can regulate NO production by these cells (Saito \& Nakano 1996). This regulation between NO and TNF- $\alpha$ can be a putative mechanism that is modulating the neutrophil migration induced by BCG in mouse pleural cavity.

\section{INVOLVEMENT OF ADHESION MOLECULES}

An important early event in the recruitment of leukocytes from the microcirculation to tissues is their interaction with vascular endothelial cells. In vitro and in vivo studies have suggested that this process involves a sequence of discrete events involving different families of cell adhesion molecules (Springer 1994). In the initial phase, leukocytes marginates to the wall of postcapillary venules and roll along the endothelial cells and this process is mediated by the selectin family of adhesion molecules (Ley et al. 1995). Then, leukocytes must firmly adhere to the vessel wall to migrate to the site of tissue irritation, a step mediated by another family of adhesion molecules the integrins (Fig. 2). The role of adhesion molecules during mycobacterial infection is not clear. We have investigated the role of integrins and L-selectin in acute cell migration induced by i.t. BCG (Fig. 3). The leukocyte integrin, CD11b/CD18 complex seems to have a role in neutrophil and mononuclear cell accumulation. Moreover the integrins CD11b/ CD18 and VLA-4, seemed to not be related with eosinophils migration whereas L-selectin appears to be responsible for the neutrophil and eosinophil migration induced by BCG (unpublished results). The role of CD11b/CD18 and L-selectin in neutrophil migration is well demonstrated in vivo with other inflammatory agents (Rossi \& Hellewell 1994).

However, the adhesion receptors involved in eosinophil recruitment at inflammation in vivo are less clearly understood. Blocking either CD18 or ICAM-1 has been shown to reduce eosinophil accumulation in vivo (Wegner et al. 1990, Teixeira et al. 1994). In addition, blocking VLA-4 in vivo has been shown to reduce eosinophil accumulation in some but not all models (Teixeira et al. 1995). Our results showed that neither the mAb anti- CD11b/ CD18 nor the anti-VLA-4 were able to inhibit eosinophil accumulation induced by BCG. One possibility is that both integrins should be simultaneously blocked to inhibit eosinophil migration as it is observed in lung eosinophilia induced by Sephadex (Das et al. 1995). Another possibility is the participation of $\alpha_{1} \beta_{2}$ or $\alpha_{4} \beta_{7}$ integrin, both de- 


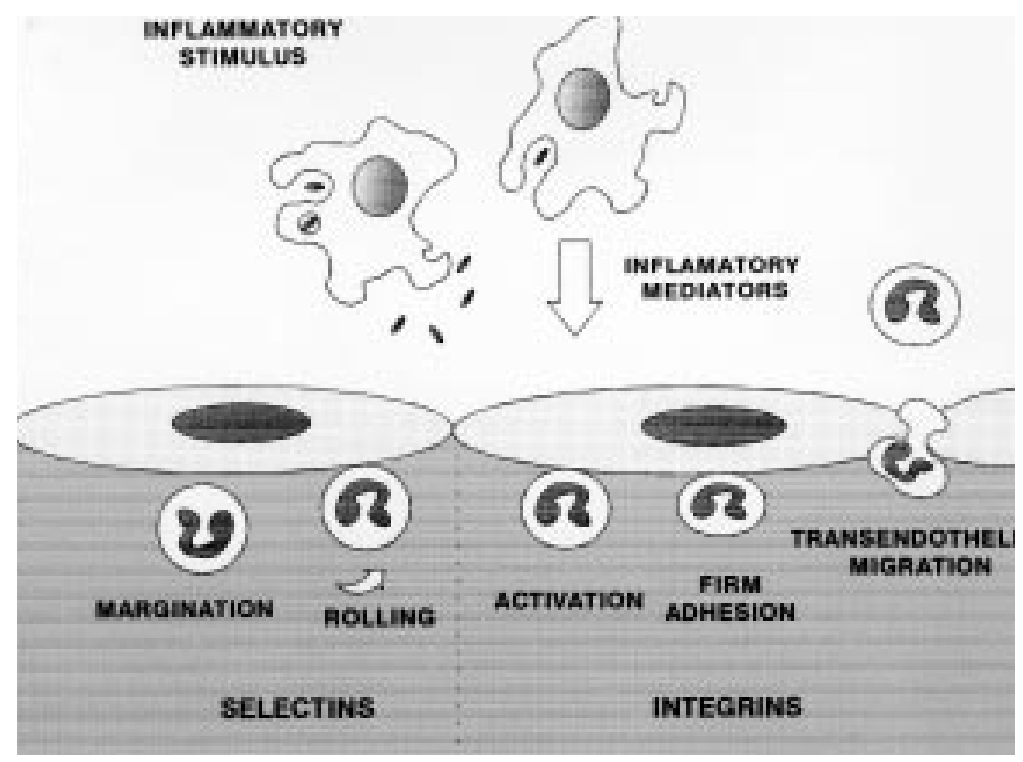

Fig. 2: leukocyte migration to the inflammatory focus.

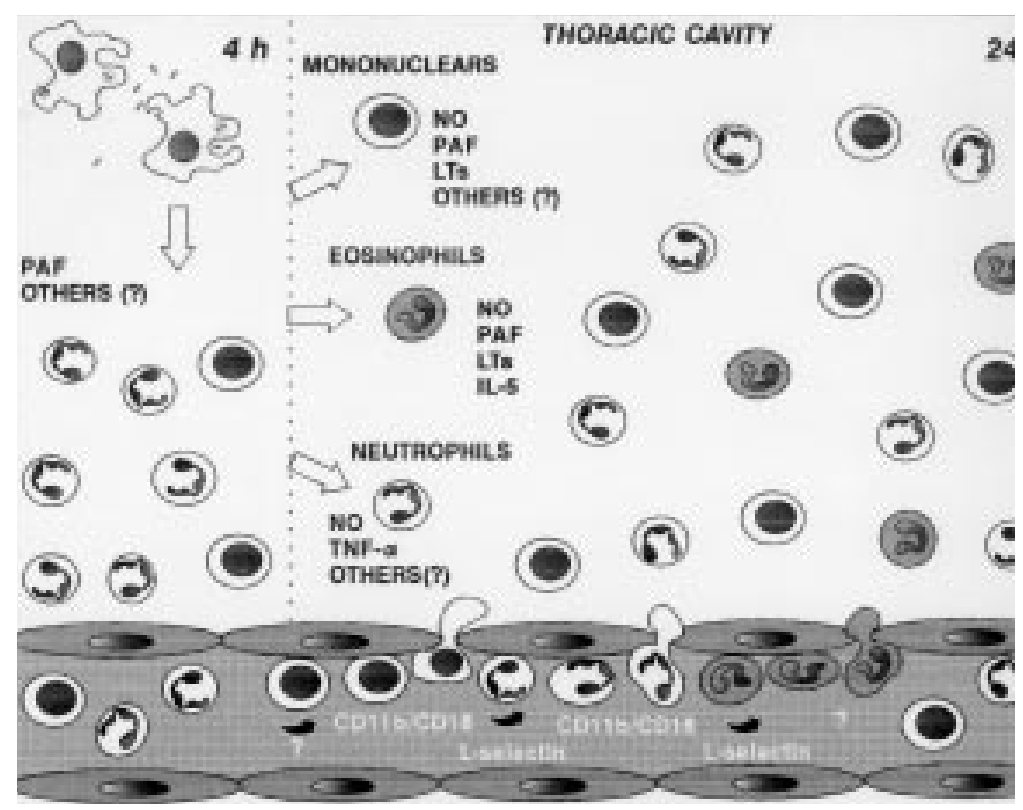

Fig. 3: inflammatory mediators, cytokines and adhesion molecules involved in the leukocyte accumulation induced by BCG in mouse pleural cavity.

scribed to be expressed in eosinophil surface (Teixeira et al. 1995, Lobb et al. 1996). A recent study in a xenogeneic mesentery model has demonstrated that the rolling of human eosinophil in IL-1 $\beta$-treated rabbit mesenteric venules is reduced in approximately $40 \%$ by anti-L-selectin mAbs (Sriramarao et al. 1994). However a role for selectins in mediating eosinophil migration to sites of inflammation in vivo has only been recently demonstrated in LPS mouse pleurisy model (Henriques et al. 1996). Our results in BCG pleu- risy model have confirmed a role for L-selectin in eosinophil influx induced by bacterial agents.

Taken together, our results have shown that mouse pleurisy induced by BCG is a useful model to study the inflammatory reaction that occurs during the primary infection with mycobacteria. This model should be helpful to improve our understanding of the role of leukocytes and cytokines in the delicate balance between strategies used by Mycobacteria to survive within a host and concomitant efforts of the host to kill it. 


\section{REFERENCES}

Antony VB, Sahn SA, Antony AC, Repine JE 1985. Bacillus Calmette-guérin-stimulated neutrophils releases chemotaxins for monocytes in rabbit pleural spaces and in vitro. J Clin Invest 76: 1514-1521.

Appelberg R 1992. Macrophage inflamatory proteins MIP-1 and MIP-2 are involved in T cell-mediated neutrophil recruitment. J Leukoc Biol 52: 303-306.

Belenky SN, Robbins RA, Rubinstein I 1993. Nitric Oxide synthase inhibitors attenuate human monocyte chemotaxis in vitro. J Leukoc Biol 53: 498-503.

Bozza PT, Castro-Faria-Neto HC, Martins MA, Larangeira AP, Perales JE, Silva PMR, Cordeiro RSB 1993. Pharmacological modulation of lipopolysaccharide-induced pleural eosinophilia in the rat; a role of a newly generated protein. Eur J Pharmacol 248 : 41-47.

Bozza PT, Castro-Faria-Neto HC, Penido C, Larangeira AP, Henriques M G M O, Silva PMR, Martins MA, Ribeiro-dos-Santos R, Cordeiro RSB 1994. Requirement for lymphocytes and resident macrophages in LPS-induced pleural eosinophil accumulation. $J$ Leukoc Biol 56: 151-160.

Castro A G, Esaguy N, Macedo P M, Aguas A P, and Silva M T 1991. Live but not heat-killed mycobacteria cause rapid chemotaxis of large numbers of eosinophils in vivo and are ingested by the attracted granulocytes. Infect Immun 59: 3009-3014.

Chrétien J 1995. Tuberculosis today. Eur Resp J 8: 617s$619 \mathrm{~s}$.

Czarnetzki BM, Csato M 1989. Comparative studies of human eosinophil migration towards platelet-activating factor and leukotriene $\mathrm{B}_{4}$. Int Arch Allergy Appl Immunol 88: 191-193.

Dannemberg, A M Jr. 1991. Delayed-type hypersensivity and cell-mediated immunity in the pathogenesis of tuberculosis. Immunol Today 12: 228-233.

Das AM, Williams TJ, Lobb R, Nourshargh S 1995. Lung eosinophilia is dependent on IL-5 and the adhesion molecules CD18 and VLA-4 in a guinea-pig model. Immunology 84: 41-46.

Fenton MJ, Vermeulen M W 1996. Immunopathology of tuberculosis: roles of macrophages and monocytes. Infect Immun 64: 683-689.

Ferreira HHA, Medeiros MV, Lima CSP, Flores CA, Sannomiya P, Antunes E, De Nucci G 1996. Inhibition of eosinophil chemotaxis by cronic blockade of nitric oxide biosynthesis. Eur J Pharmacol 310: 201207.

Griffin JFT, Mackintosh CG, Buchan GS 1995. Animal models of protective immunity in tuberculosis to evaluate candidate vaccines. Trends Microbiol 3: 418-424.

Henriques MGMO, Weg VB, Martins MA, Silva PMR, Fernandes PD, Cordeiro RSB, Vargaftig BB 1990. Differential inhibition by two hetrazepine PAF antagonists of acute inflammation in the mouse. $\mathrm{Br} \mathrm{J}$ Pharmacol 99: 164-168.

Henriques MGMO, Miotla JM, Cordeiro RSB, Wolitzky BA, Woolley ST, Hellewell PG 1996. Selectins mediate eosinophil recruitment in vivo: A comparison with their role in neutrophil influx. Blood 87: $5297-$ 5304.

Hines II ME, Kreeger JM, Herron AJ 1995. Mycobacterial infections of animals: pathology and pathogenesis. Lab Anim Sci 45: 334-351.

Issekutz AC, Issekutz TB 1992. The contribution of LFA1 (CD11a/CD18) and MAC-1 (CD11b/CD18) to the in vivo migration of polymorphonuclear leukocytes to inflammatory reactions in the rat. Immunology 76: 655-661.

Kaplan SS, Billar T, Curran RD, Zdziraski VE, Simmons RL, Basford RE 1989. Inhibition of chemotaxis with $\mathrm{N}$-monomethyl 1-arginine: a role for cyclic GMP. Blood 74: 1885-1993.

Kaufmann SHE 1993. Immunity to intracellular bacteria. Ann Rev Immunol 11: 129-163.

Ley K, Bullard DC, Arbones ML, Bosse R, Vestweber D, Tedder TF, Beaudet AL 1995. Sequential contribution of L- and P-selectin to leukocyte rolling in vivo. J Exp Med 181: 669-675.

Lobb R R, Pepinsk B, Leone DR, Abraham WM 1996. The role of $\mathrm{a}_{4}$ integrins in lung pathophysiology. Eur Resp J 9 Suppl. 22: 104s-108s.

Martins MA, Silva PMR, Castro-Faria-Neto HC, Bozza PT, Dias PMFL, Lima MCR, Cordeiro RSB,.Vargaftig BB 1989. Pharmacological modulation of PAF-induced rat pleurisy and its role in the inflammation by zymosan. Br J Pharmacol 96: 363371.

Menezes-de-Lima-Júnior O, Werneck-Barroso E, Cordeiro RSB Henriques MGMO 1996. Eosinophil accumulation induced by Mycobacterium bovis BCG in mouse pleurisy. Am J Resp Crit Care Med. Proc. ALA/ATS International Conference.

Menezes-de-Lima-Júnior O, Werneck-Barroso E, Cordeiro RSB, Henriques MGMO 1997. Effects of inhibitors of inflammatory mediators and cytokines on eosinophil and neutrophil accumulation induced by Mycobacterium bovis bacillus Calmette-Guérin in mouse pleurisy. $J$ Leukoc Biol in press.

Montgomery LG, Lemon W 1933. The cellular reaction of the pleura to infection with Mycobacterium tuberculosis. J Thorac Cardiovasc Surg 2: 429-438.

Nakamura Y, Ozaki, T, Kamei T, Kawaji K, Banno K, Miki S, Fujisawa K, Yasuoka S, Ogura T 1993. Factors that stimulate the proliferation and survival of eosinophils in eosinophilic pleural effusion: Relationship to granulocyte-macrophage colony-stimulating factor, interleukin-5, and interleukin-3. Am J Respir Cell Mol Biol 8: 605-611.

Nourshargh S 1993. Mechanisms of neutrophil and eosinophil accumulation in vivo. Am Rev Resp Dis 148 Suppl.: S60-S64.

Rossi AG, Hellewell PG 1994. Mechanisms of neutrophil accumulation in tissue, p. 223-245. In PG Hellewell, TJ Williams (eds), Immunopharmacology of Neutrophils, Academic Press, London, UK.

Saito S, Nakano M 1996. Nitric oxide production by peritoneal macrophages of Mycobacterium bovis BGC-infected or non-infected mice: regulatory roles of T lymphocytes and cytokines. J Leukoc Biol 59: 908-915. 
Smith DW, Wiegeshaus EH 1989. What animal models can teach us about the pathogenesis of tuberculosis. Rev Infect Dis II: S385-S393.

Silva PMR, Martins MA, Castro-Faria-Neto HC, Cordeiro RSB, Vargaftig BB 1991. Generation of an eosinophilotatic activity in the pleural cavity of palatelet-activating factor injected rats. J Pharmacol Exp Ther 257: 1039-1044.

Springer TA 1994. Traffic signals for lymphocyte recirculation and leukocyte emigration:The multistep paradigm. Cell 76: 301-314.

Sriramarao P, Von Andrian UH, Butcher EC, Bourdon MA, Broide DH 1994. L-selectin and very late antigen-4 integrin promote eosinophil rolling at physiological shear rates in vivo. J Immunol 153: 42384247.

Teixeira MM, Williams TJ, Hellewell PG 1993. Role of prostaglandins and nitric oxide in acute inflammatory reactions in guinea-pig skin. Br J Pharmacol 110: 1515-1522.

Teixeira MM, Reynia S, Robinson M, Shock A, Williams TJ, Williams FM, Rossi AG, Hellewell PG 1994. Role of CD18 in the accumulation of eosinophils and neutrophils and local oedema formation in inflammatory reactions in guinea pig skin. $\mathrm{Br} J$ Pharmacol 111: 811-820.

Teixeira MM, Williams TJ, Hellewell PG 1995. Mecanisms and pharmacological manipulation of eosinophil accumulation in vivo. TiPS 16: 418-423.

Vijayan V K, Rectha AM, Jawahar MS, Sankaran K, Prabhakar R 1992. Pulmonary Eosiniphilia in Pulmonary Tuberculosis. Chest 101: 1708-1709.

Wardlaw AJ, Moqbel R, Cromwell O, Kay AB 1986. Patelet-activating factor. A potent Chemotactic and chemokinetic factor for human eosinophils. J Clin Invest 78: 1701-1706.

Wergner CD, Gundel RH, Reilly P, Haynes N, Letts LG, Rothlein R 1990. Intercellular adhesion molecule-1 (ICAM-1) in the pathogenesis of asthma. Science 247: 456-460.

Werneck-Barroso E, Rosas E C, Menezes-de-Lima-Junior O, Cordeiro RSB, Assreuy-Filho J, Henriques MGMO 1996. Kinetics of inflammatory response induced by M. bovis BCG. Am J Resp Crit Care Med. Proc. ALA/ATS International Conference.

Zlotnik A, Crowde A 1982. Lymphokine-induced mycobacteriostatic activity in mouse pleural macrophages. Infect Immun 37: 786-793. 